\title{
Psychometric properties and measurement invariance of the 7-item game addiction scale (GAS) among Chinese college students
}

\author{
Yujie Liu', Qian Wang ${ }^{1 *}$ (D) Min Jou², Baohong Wang ${ }^{3}$, Yang $\mathrm{An}^{3}$ and Zifan Li ${ }^{4}$
}

\begin{abstract}
Background: The 7-item Gaming Addiction Scale (GAS) has been used as a screening tool for addictive game use worldwide, and this study aimed to examine its psychometric properties and measurement invariance among college students in China.

Methods: Full-time students from multiple colleges in China were recruited. A total of 1040 completed questionnaires were used in the final analysis. Reliability of the GAS was assessed by internal consistency and splithalf reliability. Validity of the GAS was assessed by structural validity, convergent validity, discriminant validity, and concurrent validity. A series of Multigroup Confirmatory Factor Analysis (MG-CFA) were conducted to test and establish measurement invariance across gender, class standing, family income and parental educational level.

Results: Exploratory factor analysis revealed a unidimensional structure of the GAS. The GAS exhibited excellent internal consistency (Cronbach's $a=0.951$, theta coefficient $=0.953$, omega coefficient $=0.959$ ) and structural validity $\left(X^{2} / \mathrm{df}=0.877(p<0.05), \mathrm{CFI}=0.999, \mathrm{TIL}=0.996, \mathrm{RMSEA}=0.000\right)$. Concurrent validity of the GAS was confirmed by its correlation with problematic internet use, sleep quality, nine dimensions of psychiatric symptoms, and substance use. The GAS also demonstrated measurement invariance across father's educational level $(\Delta x 2(\mathrm{df})=19.128(12)$, $\Delta \mathrm{CFI}=-0.009, \Delta \mathrm{RMSEA}=0.010$ for weak factorial model; $\Delta \mathrm{X} 2(\mathrm{df})=50.109(42), \Delta \mathrm{CFI}=-0.010, \Delta \mathrm{RMSEA}=0.007$ for strict factorial model.) and mother's educational level $(\Delta \mathrm{X} 2(\mathrm{df})=6.679(12), \Delta \mathrm{CFI}=0.007, \Delta \mathrm{RMSEA}=-0.010$ for weak factorial model; $\Delta \mathrm{X} 2$ (df) $=49.131$ (42), $\Delta \mathrm{CFI}=-0.009, \Delta \mathrm{RMSEA}=-0.004$ for strict factorial model), as well as partial measurement invariance across gender (except for item 2), class standing (except for item 7) and family income (except for item 5).
\end{abstract}

Conclusions: The Chinese version of the 7-item GAS can be an adequate assessment tool to assess internet gaming disorder among the college student population in China.

Keywords: Internet gaming disorder, College students, PSQI, SCL-90-R, Internet addiction, Measurement invariance

\footnotetext{
* Correspondence: qian.wang@shsmu.edu.cn

'School of Public Health, Shanghai Jiao Tong University School of Medicine,

No 227 S Chongqing Road, Shanghai 200025, China

Full list of author information is available at the end of the article
}

\section{$\triangle B M C$}

(c) The Author(s). 2020 Open Access This article is licensed under a Creative Commons Attribution 4.0 International License, which permits use, sharing, adaptation, distribution and reproduction in any medium or format, as long as you give appropriate credit to the original author(s) and the source, provide a link to the Creative Commons licence, and indicate if changes were made. The images or other third party material in this article are included in the article's Creative Commons licence, unless indicated otherwise in a credit line to the material. If material is not included in the article's Creative Commons licence and your intended use is not permitted by statutory regulation or exceeds the permitted use, you will need to obtain permission directly from the copyright holder. To view a copy of this licence, visit http://creativecommons.org/licenses/by/4.0/ The Creative Commons Public Domain Dedication waiver (http://creativecommons.org/publicdomain/zero/1.0/) applies to the data made available in this article, unless otherwise stated in a credit line to the data. 


\section{Background}

Internet gaming disorder (IGD) has increasingly become an internationally recognized behavioral addiction, constituting a growing concern worldwide including in China. Its inclusion in the fifth edition of the Diagnostic and Statistical Manual of Mental Disorders (DSM-V [1];) has garnered considerable attention from researchers worldwide. The DSM-V clearly defines the diagnostic criteria for IGD, requiring at least 5 out of 9 symptoms (preoccupation, tolerance, escape, withdrawal, persistence, conflict, problems, deception, and displacement) to be present for at least 12 months. Prevalence of IGD varied across countries (ranging from $1.6 \%$ in the Netherlands to $3.0 \%$ in Germany), with higher rates consistently reported for adolescents residing in Asia (i.e. $10.3 \%$ in mainland China) [2]. In China, the prevalence of IGD varied widely, ranging from 3.9\% for high school students in Shanghai to $15.6 \%$ for secondary school students in Hong Kong [3, 4]. The discrepancies in prevalence rates of IGD have been largely attributed to measurement issues such as heterogeneity in assessment tools [5], or lack of measurement invariance across different groups. Such issues may confound accurate assessment of IGD prevalence, affecting the screening or identification of high-risk groups. Therefore, it is important for relevant instruments to be psychometrically evaluated in different populations.

The present study sought to address this aim by assessing the psychometric properties of the widely-used 7item Game Addiction Scale (GAS) developed by Lemmens et al. [6]. The GAS was created in view of the substantial overlap between personality characteristics of gamblers and gaming addicts [6, 7], and has been used in various populations as an assessment tool to screen for IGD. Items on the GAS were adapted from the 7 diagnostic criteria (salience, tolerance, mood modification, withdrawal, relapse, conflict, and problems) for pathological gambling under DSM-IV-TR [6], and were confirmed as adequate to assess IGD among two independent samples of adolescents in Netherlands [6]. Concurrent validity of the GAS was found to be satisfactory, indicated by the correlations between scores on the GAS and time spent on games $(r=0.576)$, life satisfaction $(r=$ - 0.136), loneliness $(r=0.314)$, social competence $(r=-$ $0.158)$ and aggression $(r=0.265)$ [6]. Psychometric properties of the scale were later tested among gamers as well as the general population residing in France, Germany, Brazil, Spain, Iran and Italy [8-12]. Confirmatory factor analysis (CFA) showed that the scale had a unidimensional structure [9], with a Cronbach's alpha value ranging from 0.85 [9] to 0.92 [10]. Although the GAS has been used to examine prevalence and correlates of IGD among adolescents and young adults in China [3, 13, 14], no study has focused on its psychometric properties in this population. Understanding and evaluating psychometric properties of the GAS in this population is an essential aspect of scale selection, it may enhance applicability of the scale and accuracy of the scale in identifying at-risk populations.

In the current study, we chose to assess psychometric properties of the GAS among the college student population in China for the following reasons: the adolescent population has been the main focus of existing studies, whereas the young adult population has been underresearched, as it is commonly perceived that, compared to other age groups, characteristics unique to adolescents may make them more vulnerable to developing IGD [15-18]. However, it is critical to note that adolescents in China typically face intense academic pressure due to fierce competitions in the college entrance exam, or Gaokao. In comparison, once students enter college in China, they are completely relieved of the academic pressure of Gaokao, and most likely divert their attention to other aspects of their college life [19]. Second, most adolescents live with their parents during their junior and high school years, when close proximity to parents can facilitate and strengthen parental monitoring. In comparison, many students choose to attend college away from their hometown and parents, a sign of independence, which may lead to decreased parental control and monitoring. A study examining health-related behaviors among middle school, high school and college students in China found screen time increased as educational level increased [20]. A recent study examining both high school and college students in China found college students scored higher on the IGD-20 Test [13].

Therefore, the purpose of this study was to assess the reliability and validity of the 7 -item GAS using a sample of college students residing in China. We further assessed the association of IGD with mental health, sleep quality, substance use, problematic internet use, and social media addiction in establishing the validity of the GAS. Additionally, we sought to test and establish measurement invariance of the GAS across sociodemographic groups. Examining measurement invariance is an essential aspect of instrument validation, as it reflects the extent to which a measured construct has the same meaning across all respondents regardless of their group membership [21]. Findings of this study could expand the applicability of the 7-item GAS in assessing IGD to the Chinese college student population, and lay the ground work for further analysis and comparison.

\section{Methods}

\section{Participants}

A convenient sample of 1071 participants was recruited from multiple colleges in mainland China. Students who 
were attending school part-time or unable to complete the questionnaire were excluded, only full-time students who were willing to complete the questionnaire were included. We only included full-time students on the grounds that part-time or non-traditional students are usually older compared to traditional-age college students, and may enter college with work experience or family situations that can predispose them to a much different pattern of internet use behavior. As a result, respondents indicating they were graduate students $(15$, $1.40 \%)$ were excluded from final analysis. We checked the remaining data for missing values, and found 16 cases $(1.49 \%)$ had missing values in the variable sleep efficiency, while all other cases had complete responses in every variable used in the analysis. As Schafer et al. suggested that a missing rate of $5 \%$ or less is commonly inconsequential [44], we performed complete case analysis. The final sample consisted of 1040 traditionalage college students, 416 of whom were males $(40 \%)$ and 624 were females $(60 \%)$. The maximum estimated sampling error of our sample was calculated to be $\pm 3.04 \%$ with a $95 \%$ confidence probability [57].

\section{Measures}

\section{Internet gaming addiction (IGD)}

IGD was measured by the Gaming Addiction Scale (GAS) developed by Lemmens et al. The GAS consists of seven Likert-type items $(1=$ never, $2=$ rarely, $3=$ sometimes, $4=$ often, $5=$ very often), which all begin with a statement "During the last 6 months, how often ..." For example, "During the last 6 months, how often did you think about playing a game all day long?" Total score of the GAS is between 7 and 35, with higher scores indicating higher level of gaming addiction. Chinese version of the GAS was utilized to test IGD among adolescents, with a Chronbach's alpha value between 0.93 and 0.94 [3]. Concurrent validity of the GAS has been confirmed by its correlation with Internet Addiction and hours of gaming among Italian adolescents [8]. Good internal reliability was reported in the present study (Chronbach's alpha value $=0.951)$.

\section{Problematic internet use}

Problematic internet use was assessed by Young's 20item Internet Addiction Test (IAT) [58]. The scale was developed based on the diagnostic criteria for pathological gambling under the DSM-IV-TR. Each item is rated using a Likert scale $(1=$ never, $2=$ rarely, $3=$ sometimes, $4=$ often, $5=$ very often). For example, "How often do you find that you stay online longer than you intended?" The total score of the IAT is between 20 and 100. Chinese version of the IAT has demonstrated good internal consistency (Cronbach's alpha $=0.93$ [22];). Concurrent validity of the IAT has also been confirmed by its correlation with the Revised Chen Internet Addiction Scale $(r=0.46$ [22];), the average online time per day ( $r=0.40$ for weekdays, $r=0.37$ for weekends [22];), and the Mobile Phone Dependence Questionnaire $(r=$ 0.59 [23];). Good internal reliability was reported in the present study (Chronbach's alpha value $=0.938$ ).

\section{Sleep quality}

Sleep quality was assessed using the Pittsburgh Sleep Quality Index (PSQI). The PSQI consists of 18 items that measure seven dimensions of sleep quality over the past month [24]: subjective sleep quality, sleep latency, sleep duration, habitual sleep efficiency, sleep disturbances, use of sleep medication, and daytime dysfunction. For example, "During the past month, how often have you had trouble sleeping because you have pain?" The total score of each dimension ranges from 0 to 3, with higher scores indicating poorer sleep quality. The total score of the whole scale is obtained by summing scores on each of the seven dimensions, ranging from 0 to 21. Chinese version of the PSQI has exhibited adequate internal consistency [25]. Consistent with values (0.62-0.66) reported in previous studies [25, 26], Cronbach's alpha for the scale in the present study was 0.64 and considered to be acceptable. Composite reliability for the scale was 0.78 , exceeding the recommended minimum value of 0.7 [49].

\section{Psychiatric symptoms}

Psychiatric symptoms were assessed using the Symptom Checklist 90-Revised (SCL-90-R) [27]. The SCL-90-R is a widely used self-report scale consisting of 90 items that examines nine symptomatic dimensions: somatization, obsessive-compulsiveness, interpersonal sensitivity, depression, anxiety, hostility, phobic anxiety, paranoid ideation, and psychoticism. An example of the items would be "How much were you bothered or distressed over the past 4 weeks by headaches?" The score of each item ranges from 0 to $5(0=$ not at all, $1=$ a little bit, $2=$ moderately, 3 =quite a bit, $4=$ extremely), and score of each item is summed up to produce a total score between 0 and 360. Chinese version of the SCL-90-R exhibited good internal consistency (Cronbach's $\alpha=0.98$ ) [28]. Scores on the nine subscales were significantly correlated with scores on the whole scale, indicating good structural validity $[28,29]$. Criterion validity of the SCL90- $\mathrm{R}$ has also been examined through its correlation with self-reported quality of life [28]. Cronbach's alpha value for the scale was 0.977 in the current study.

\section{Substance use}

Substance use, including tobacco use, binge drinking and other drug use, were assessed within a 12-month time period. Tobacco use was assessed by asking 
whether respondents had used either traditional cigarettes or e-cigarettes. Binge drinking was assessed by asking whether respondents had at least had five drinks (including beer, wine, champagne and liquor) in one setting for males, and at least had four drinks in one setting for females. Other drug use was assessed by asking whether respondents had used marijuana, heroin, MDMA, sedatives, or over the counter (OTC) medications. Because the number of positive responses to each type of other drug use was relatively low, we combined responses to each type of other drug use into a single binary variable, comparing with those used at least one type of other drugs against those who answered "no" to all types of other drug use.

\section{Social media addiction}

Social media addiction was assessed by the Social Media Addiction Scale - Student Form (SMA-SF) developed by Sahin [30]. The scale consists of 29 items measuring 4 dimensions of social media addiction: virtual tolerance, virtual communication, virtual problem and virtual information. Total score of the SMA-SF ranges from 29 to 145 , with higher scores indicating higher levels of social media addiction [30]. Each item can be rated on a 5-point Likert-type scale $(1=$ Definitely not appropriate, $2=$ Not appropriate, $3=$ Undecided, $4=$ Appropriate, $5=$ Quite appropriate) In the original study, the SMA-SF exhibited good internal reliability (Cronbach's alpha $=0.93$ ), splithalf reliability (Guttmann Split-Half value $=0.90$ ) and testretest reliability (test-retest coefficient $=0.94$ ). In this study, the SMA-SF demonstrated good internal reliability, the value of Cronbach's alpha for the scale was calculated to be 0.955 .

\section{Procedure}

We used a popular professional online survey platform (https://www.wjx.cn/) in China to prepare and present the survey. Recruitment occurred between June to August, 2019. The link to the survey was distributed via Wechat messages. All participants were informed that participation was completely anonymous and that their responses would be kept confidential. Upon completion of the survey, each participant was given 2 Chinese yuan (about \$0.3 USD).

\section{Statistical analysis}

All analyses were conducted using SPSS 22.0 and AMOS 24.0. Reliability of the scale was assessed by internal consistency and split-half reliability. Validity of the scale was assessed by structural validity, convergent validity, discriminant validity, and concurrent validity.

\section{Reliability}

Internal consistency represents the extent to which different items are correlated, and was assessed using Cronbach's alpha coefficients, theta coefficient and omega coefficient [31]. A coefficient of greater than 0.7 indicates good internal consistency [32]. Split-half reliability indicates stability of the scale, and was measured using the Spearman-Brown coefficient, with higher values representing higher stability [33].

\section{Validity}

Exploratory factor analysis (EPA) was conducted to examine the factor structure of the GAS. Previous studies have found the 7-item GAS to have a unidimentional structure [6]. Confirmatory factor analysis (CFA) was used to measure structural validity of the GAS. The goodness-of-fit of the model was examined using a series of indices: the $x^{2}$ to degrees of freedom ratio $\left(x^{2} / d f\right)$, comparative fit index (CFI), goodness of fit index (GFI) and root mean square error of approximation (RMSEA). The assessment criteria for each index were: $\mathrm{X}^{2} / \mathrm{df}<3, \mathrm{CFI}>0.9$, GFI $>0.9$ and RMSEA $<0.08$ [34].

Convergent validity of the scale was measured by the value of average variance extracted (AVE), which was calculated using a formula $\frac{\left.\sum \text { (factor loading value }\right) 2}{\left.\left.\sum \text { (factor loading value }\right) 2+\sum \text { (measurement error }\right)}$. The convergent validity of a scale is considered acceptable if the value of AVE is higher than 0.50 [35]. Concurrent validity was measured by the association between the GAS and the IAT, PSQI, SCL-90 and substance use. The Pearson product-moment correlation coefficient was used to assess their associations. The correlation coefficient ranges between -1.0 and 1.0, an absolute value of $\geq 0.5$ is considered large, an absolute value between 0.3 and 0.5 is considered moderate, an absolute value between 0.1 and 0.3 is considered small, and an absolute value less than 0.1 is considered trivial [36]. Discriminant validity refers to whether dissimilar constructs can be differentiated, and was measured by the correlation between GAS and SMA-SF in the present study. A Pearson's value of less than 0.85 indicates adequate discriminant validity [35].

Multigroup confirmatory factor analysis (MCFA) was conducted to test the measurement invariance of the GAS across gender, class standing, income and parental educational level. Three nested models were adopted: 1 ) a configural model (model 1), in which all factor parameters were freely estimated; 2 ) a weak factorial invariance model (model 2), in which item loadings were constrained to be equal across groups; and 3) a strict factorial invariance model (model 3), in which item residuals were constrained to be equal across groups. Chen [37] recommends that measurement invariance is not supported if CFI decreases by a value greater than 0.01 or RMSEA increases by a value greater than 0.015 [37]. 
Because the GAS is an ordinal scale, maximum likelihood estimation may not be the appropriate estimate, asymptotically distribution-free estimation was used to accommodate non-normally distributed data in SEM analyses instead.

\section{Ethics}

The study procedures were carried out according to the Declaration of Helsinki. The Institutional Review Board of the [Name of the Institution] approved this study. All participants were informed about the study, and all provided informed consent.

\section{Results}

Sample characteristic of the final 1040 respondents (416 male and 624 female) were shown in Table 1.

\section{Reliability}

The GAS exhibited satisfactory internal consistency and split-half reliability, with Cronbach's alpha value of 0.951 , theta coefficient value of 0.953 , omega coefficient value of 0.959 , and a Spearman-Brown coefficient value of 0.938. All the items demonstrated good corrected item-total correlations, ranging from 0.781 to 0.867 (Table 2).

\section{Validity}

\section{Structural validity, convergent validity and discriminant} validity

EFA revealed a one-factor model of the GAS, which was further confirmed by CFA. The model exhibited satisfactory fit indices: $X^{2} / \mathrm{df}=0.877(p<0.05), \mathrm{CFI}=0.999$, GFI $=0.996$, RMSEA $=0.000(90 \% \mathrm{CI}=0.000,0.035)$. In addition, no standardized factor loading was below 0.76 (Table 3). The GAS exhibited good convergent and discriminant validity, with the AVE value to be 0.734 and the value of Pearson's correlation coefficient to be 0.520 (Table 3).

\section{Concurrent validity}

As shown in Table 4, correlation between the GAS total score and the IAT total score was large $(r=0.672)$. Correlation between the GAS total score and the SCL-90-R total score $(r=0.455)$ and subscale scores was moderate, somatization $(r=0.483)$, obsessive-compulsive symptoms $(r=0.382)$, interpersonal sensitivity $(r=0.390)$, depression $(r=0.414)$, anxiety $(r=0.440)$, hostility $(r=0.457)$, phobic anxiety $(r=0.467)$, paranoid ideation $(r=0.457)$, and psychoticism $(r=0.427)$. Correlation between the GAS total score and substance use total score was also moderate $(r=0.367)$. However, the correlation of GAS total score with PSQI total score was small $(r=0.220)$.
Table 1 Sample characteristics

\begin{tabular}{|c|c|}
\hline Characteristics & Total $(n=1040)$ \\
\hline \multicolumn{2}{|l|}{ Gender } \\
\hline Male & $416(40 \%)$ \\
\hline Female & $624(60 \%)$ \\
\hline \multicolumn{2}{|l|}{ Class standing } \\
\hline Freshmen & $264(25.4 \%)$ \\
\hline Sophomores & $491(47.2 \%)$ \\
\hline Juniors \& Seniors & $285(27.4 \%)$ \\
\hline \multicolumn{2}{|l|}{ Family income } \\
\hline$<50,000$ & $241(23.2 \%)$ \\
\hline $50,000 \sim 100,000$ & 309 (29.7\%) \\
\hline $50,000 \sim 200,000$ & 302 (29.0\%) \\
\hline$>200,000$ & $188(18.1 \%)$ \\
\hline \multicolumn{2}{|l|}{ Father's educational level } \\
\hline$\leq$ Middle school & 381 (36.3\%) \\
\hline High school & $258(24.8 \%)$ \\
\hline$\geq$ College & $401(38.6 \%)$ \\
\hline \multicolumn{2}{|l|}{ Mother's educational level } \\
\hline$\leq$ Middle school & $436(41.9 \%)$ \\
\hline High school & $250(24.0 \%)$ \\
\hline$\geq$ College & $354(34.0 \%)$ \\
\hline Internet gaming disorder & $16.41(7.07)$ \\
\hline Problematic internet use & $54.09(16.29)$ \\
\hline Sleep quality & $5.45(2.92)$ \\
\hline \multicolumn{2}{|l|}{ Psychological symptom } \\
\hline Interpersonal sensitivity & $6.38(7.36)$ \\
\hline Depression & $8.81(10.56)$ \\
\hline Anxiety & $5.58(7.58)$ \\
\hline Hostility & $3.40(4.64)$ \\
\hline Phobic anxiety & $3.35(5.24)$ \\
\hline Paranoid ideation & $3.31(4.59)$ \\
\hline Phychoticism & $5.62(7.62)$ \\
\hline Socia media addiction & $81.29(22.77)$ \\
\hline \multicolumn{2}{|l|}{ Substance use } \\
\hline Past-year tobacco use & 179 (17.2\%) \\
\hline Past-year binge drinking & $276(26.5 \%)$ \\
\hline Past-year substance use & $304(29.2 \%)$ \\
\hline
\end{tabular}

Note: Values are presented as mean (SD) or number (percentage) when appropriate

\section{Measurement invariance}

Model fit indices across gender, class standing, family income and parental educational level are presented in Table 5. Results indicated that the GAS had strict measurement invariance across educational level of father and mother respectively, supported by the acceptance of model 2 and model 3. Model fit indices including $\Delta \mathrm{x} 2$ (df), $\Delta$ CFI 
Table 2 Corrected item-total correlation and reliability indices

\begin{tabular}{lll}
\hline Item & Construct & $\begin{array}{l}\text { Corrected item-total } \\
\text { correlation }\end{array}$ \\
\hline item1 & Salience & 0.849 \\
item2 & Tolerance & 0.781 \\
item3 & Mood modification & 0.855 \\
item4 & Relapse & 0.867 \\
item5 & Withdrawal & 0.835 \\
item6 & Conflict & 0.830 \\
item7 & Problems & 0.841 \\
Chronbach a & & 0.951 \\
Theta coefficient & & 0.953 \\
Omega coefficient & & 0.959 \\
Spearman-Brown Coefficient & & 0.938 \\
\hline
\end{tabular}

and $\triangle$ RMSEA are presented in Table 6. For gender, values of model fit indices were $\Delta \mathrm{X}^{2}(\mathrm{df})=14.910$ (6), $\Delta \mathrm{CFI}=-$ 0.013, $\triangle$ RMSEA $=0.014$ for weak factorial model, and $\Delta \mathbf{X}^{2}$ $(\mathrm{df})=105.666(21), \Delta \mathrm{CFI}=-0.120, \Delta \mathrm{RMSEA}=0.041$ for strict factorial model. For class standing, values of model fit indices were $\Delta \mathrm{X}^{2} \quad(\mathrm{df})=26.129 \quad(12), \Delta \mathrm{CFI}=-0.016$, $\triangle$ RMSEA $=0.019$ for weak factorial model, and $\Delta \mathrm{X}^{2}(\mathrm{df})=$ 72.809 (42), $\Delta$ CFI $=-0.037, \triangle$ RMSEA $=0.021$ for strict factorial model. For family income, values of model fit indices were $\Delta \mathrm{X}^{2}(\mathrm{df})=21.76(12), \Delta \mathrm{CFI}=-0.011, \Delta \mathrm{RMSEA}=$ 0.005 for weak factorial model, and $\Delta \mathrm{X}^{2}(\mathrm{df})=78.121$ (42), $\Delta \mathrm{CFI}=-0.042, \Delta \mathrm{RMSEA}=0.010$ for strict factorial model. Results of model 2 and 3 revealed that the GAS exhibited no weak or strict measurement invariance across gender, class standing and family income.

Considering the rejection of weak measurement invariance across gender, class standing and family income,

Table 3 Standardized factor loading, goodness-of-fit indices, convergent and discriminant validity indices

\begin{tabular}{lll}
\hline Item & Construct & Factor loading \\
\hline item1 & Salience & 0.86 \\
item2 & Tolerance & 0.76 \\
item3 & Mood modification & 0.89 \\
item4 & Relapse & 0.88 \\
item5 & Withdrawal & 0.87 \\
item6 & Conflict & 0.87 \\
item7 & Problems & 0.86 \\
X2 /df & & 0.877 \\
CFI & & 0.999 \\
GFI & & 0.996 \\
RMSEA & & 0.000 \\
AVE & & 0.734 \\
Pearson'r & & 0.520 \\
\hline
\end{tabular}

partial invariance for each item was further examined. For gender, after checking the result of measurement invariance, item 2 had the largest value. So the loading of item 2 was set to vary and the weak measurement invariance was tested again. Values of model fit indices were $\Delta \mathrm{X}^{2}(\mathrm{df})=6.027$ (5), $\Delta \mathrm{CFI}=-0.002, \Delta \mathrm{RMSEA}=0.002$, indicating that partial invariance was supported for gender when the loading of item 2 was set to vary. The same process of setting free the loading of the item with the largest measurement invariance until $|\Delta \mathrm{CFI}|<0.01$ and $\triangle$ RMSEA $<0.015$ was repeated for class standing and family income. As shown in Table 7, the noninvariant factors were salience, mood modification, relapse, withdrawal, conflict and problems for gender; salience, tolerance, mood modification, relapse, withdrawal and conflict for class standing; salience, tolerance, mood modification, relapse, conflict and problems for family income.

\section{Discussion}

This study is the first to examine the psychometric properties and measurement invariance of the 7-item GAS among Chinese college students. Consistent with results from previous studies, [9-11], we found the GAS had a unidimensional structure and exhibited excellent reliability. Our findings on measurement invariance of the GAS across different sociodemographic groups lent support to existing studies that found measurement invariance of the GAS across linguistic groups [9], gender and groups spending different amounts of time on gaming [11]. More specifically, we found the GAS had strict measurement invariance across parental educational levels, suggesting that scores on the GAS reflected respondents' gaming behaviors rather than the influence of their parents' level of education. We also found partial measurement invariance was supported for gender, class standing and family income groups. That is, all items except for tolerance were found to be operating equivalently across gender; all items except for problems were found to be operating equivalently across class standing; all items except for withdrawal were found to be operating equivalently across family income. According to a previous study, the imprecision of the concept of withdrawal may cause unexplained variance in different groups [9]. Our study further revealed the relative weakness of the items of problems and tolerance when assessing internet gaming addiction among the Chinese college student population.

Our results indicated a moderate association between the scores on the GAS and the total as well as subscale scores on the SCL-90-R. This finding was consistent with previous studies reporting the association between IGD and subscales of SCL-90-R such as depression, 
Table 4 Correlations between GAS and other constructs

\begin{tabular}{|c|c|c|c|c|c|c|c|c|c|c|c|c|c|}
\hline & 1 & 2 & 3 & 4 & 5 & 6 & 7 & 8 & 9 & 10 & 11 & 12 & 13 \\
\hline 1.GAS & 1.00 & 0.67 & 0.22 & 0.48 & 0.38 & 0.39 & 0.41 & 0.44 & 0.46 & 0.47 & 0.46 & 0.43 & 0.37 \\
\hline 2.IAT & & 1.00 & 0.31 & 0.43 & 0.45 & 0.43 & 0.45 & 0.43 & 0.43 & 0.42 & 0.43 & 0.41 & 0.26 \\
\hline 3.PSQI & & & 1.00 & 0.42 & 0.48 & 0.44 & 0.47 & 0.45 & 0.42 & 0.39 & 0.42 & 0.41 & 0.20 \\
\hline 4.Somatization (subscale) & & & & 1.00 & 0.82 & 0.82 & 0.86 & 0.91 & 0.87 & 0.90 & 0.88 & 0.87 & 0.61 \\
\hline 5.Obsessive-compulsiveness (subscale) & & & & & 1.00 & 0.91 & 0.91 & 0.88 & 0.84 & 0.82 & 0.85 & 0.86 & 0.43 \\
\hline 6.interpersonal sensitivity (subscale) & & & & & & 1.00 & 0.93 & 0.90 & 0.88 & 0.85 & 0.90 & 0.90 & 0.46 \\
\hline 7.Depression (subscale) & & & & & & & 1.00 & 0.93 & 0.88 & 0.87 & 0.89 & 0.91 & 0.49 \\
\hline 8.Anxiety (subscale) & & & & & & & & 1.00 & 0.92 & 0.91 & 0.92 & 0.93 & 0. \\
\hline 9.Hostility (subscale) & & & & & & & & & 1.00 & 0.89 & 0.91 & 0.89 & 0.55 \\
\hline 10.Phobic anxiety (subscale) & & & & & & & & & & 1.00 & 0.89 & 0.89 & 0. \\
\hline 11.Paranoid ideation (subscale) & & & & & & & & & & & 1.00 & 0.92 & 0.55 \\
\hline 12.Psychoticism (subscale) & & & & & & & & & & & & 1.00 & 0. \\
\hline 13.Substance use & & & & & & & & & & & & & \\
\hline
\end{tabular}

Note: GAS Gaming Addiction Scale, IAT Internet Addiction Test, PSQI Pittsburgh Sleep Quality Index, SCL-90-R Symptom Checklist-90-Revised

anxiety, somatization [38-40], interpersonal sensitivity, obsessive-compulsiveness, phobic anxiety, hostility [40], psychoticism and overall severity [41]. Although gaming may be a way to cope with psychological distress, yet, excessive gaming can result in elevated levels of depression, anxiety and social phobia [42]. Moreover, excessive gaming may lead to increased risk of exposure to violent games, as gaming addicts seemed to have more normative beliefs about aggressions and to engage in more hostile behaviors [42]. The overlap between IGD and obsessive-compulsiveness may be attributed to impairment in inhibitory control, which may lead to repetitive dysfunctional behaviors [43]. Excessive gaming was also associated with reduced motivation in other social

Table 5 Factor loading and model fit across gender, class standing, family income and parental educational level

\begin{tabular}{|c|c|c|c|c|c|c|c|c|c|c|c|}
\hline \multirow[b]{2}{*}{ Item } & \multicolumn{7}{|c|}{ Factor loading } & \multicolumn{4}{|c|}{ Model fit } \\
\hline & Item1 & Item2 & Item3 & Item4 & Item5 & Item6 & Item7 & $x^{2} / d f$ & CFI & GFI & RMSEA \\
\hline \multicolumn{12}{|l|}{ Gender } \\
\hline Male & 0.80 & 0.72 & 0.87 & 0.85 & 0.83 & 0.84 & 0.85 & 0.714 & 1.000 & 0.996 & 0.000 \\
\hline Female & 0.90 & 0.8 & 0.91 & 0.90 & 0.89 & 0.87 & 0.88 & 1.411 & 0.99 & 0.983 & 0.026 \\
\hline \multicolumn{12}{|l|}{ Class standing } \\
\hline Freshmen & 0.90 & 0.75 & 0.93 & 0.87 & 0.92 & 0.86 & 0.98 & 1.469 & 0.981 & 0.976 & 0.042 \\
\hline Sophomores & 0.85 & 0.76 & 0.89 & 0.88 & 0.84 & 0.89 & 0.83 & 0.537 & 1.000 & 0.994 & 0.000 \\
\hline Juniors \& Seniors & 0.85 & 0.84 & 0.87 & 0.91 & 0.88 & 0.84 & 0.90 & 0.764 & 1.000 & 0.993 & 0.000 \\
\hline \multicolumn{12}{|l|}{ Family income } \\
\hline$<50,000$ & 0.856 & 0.773 & 0.93 & 0.931 & 0.89 & 0.919 & 0.897 & 0.898 & 1.000 & 0.987 & 0.000 \\
\hline $50,000 \sim 100,000$ & 0.859 & 0.785 & 0.887 & 0.834 & 0.914 & 0.85 & 0.874 & 1.179 & 0.995 & 0.985 & 0.024 \\
\hline $50,000 \sim 200,000$ & 0.871 & 0.825 & 0.881 & 0.878 & 0.854 & 0.844 & 0.873 & 0.939 & 1.000 & 0.986 & 0.000 \\
\hline$>200,000$ & 0.855 & 0.77 & 0.884 & 0.893 & 0.898 & 0.879 & 0.876 & 1.825 & 0.973 & 0.972 & 0.066 \\
\hline \multicolumn{12}{|c|}{ Father's educational level } \\
\hline$\leq$ Middle school & 0.877 & 0.818 & 0.899 & 0.911 & 0.894 & 0.9 & 0.852 & 1.037 & 0.999 & 0.990 & 0.010 \\
\hline High school & 0.856 & 0.724 & 0.925 & 0.894 & 0.851 & 0.869 & 0.905 & 1.072 & 0.998 & 0.987 & 0.010 \\
\hline$\geq$ College & 0.845 & 0.81 & 0.871 & 0.851 & 0.876 & 0.831 & 0.867 & 0.981 & 1.000 & 0.985 & 0.000 \\
\hline \multicolumn{12}{|c|}{ Mother's educational level } \\
\hline$\leq$ Middle school & 0.894 & 0.789 & 0.902 & 0.908 & 0.894 & 0.887 & 0.894 & 1.836 & 0.986 & 0.985 & 0.044 \\
\hline High school & 0.871 & 0.814 & 0.896 & 0.842 & 0.867 & 0.894 & 0.829 & 1.041 & 0.999 & 0.985 & 0.013 \\
\hline$\geq$ College & 0.886 & 0.816 & 0.879 & 0.902 & 0.886 & 0.765 & 0.842 & 1.279 & 0.989 & 0.978 & 0.028 \\
\hline
\end{tabular}


Table 6 Measurement invariance across gender, class standing, family income and parental educational level

\begin{tabular}{|c|c|c|c|c|c|c|c|}
\hline \multirow[t]{2}{*}{ Model } & & \multicolumn{6}{|c|}{ Model Fit Indices } \\
\hline & & $x^{2}(d f)$ & $\Delta \times 2(\Delta d f)$ & $\mathrm{CFI}$ & $\Delta \mathrm{CFI}$ & RMSEA & $\overline{\triangle R M S E A}$ \\
\hline \multirow[t]{3}{*}{ Gender } & Configural & $14.876(14)$ & & 0.999 & & 0.008 & \\
\hline & Weak factorial & $29.786(20)$ & $14.910(6)$ & 0.986 & -0.013 & 0.022 & 0.014 \\
\hline & Strict factorial & $120.542(35)$ & $105.666(21)$ & 0.879 & -0.120 & 0.049 & 0.041 \\
\hline \multirow[t]{3}{*}{ Class standing } & Configural & $19.403(21)$ & & 1.000 & & 0.000 & \\
\hline & Weak factorial & $45.532(33)$ & $26.129(12)$ & 0.984 & -0.016 & 0.019 & 0.019 \\
\hline & Strict factorial & $92.212(63)$ & $72.809(42)$ & 0.963 & -0.037 & 0.021 & 0.021 \\
\hline \multirow[t]{3}{*}{ Family income } & Configural & $55.048(49)$ & & 0.993 & & 0.011 & \\
\hline & Weak factorial & $76.808(61)$ & $21.76(12)$ & 0.982 & -0.011 & 0.016 & 0.005 \\
\hline & Strict factorial & 133.169 (91) & $78.121(42)$ & 0.951 & -0.042 & 0.021 & 0.010 \\
\hline \multirow[t]{3}{*}{ Education(F) } & Configural & $21.631(21)$ & & 0.999 & & 0.005 & \\
\hline & Weak factorial & 40.759 (33) & $19.128(12)$ & 0.990 & -0.009 & 0.015 & 0.010 \\
\hline & Strict factorial & 71.74 (63) & $50.109(42)$ & 0.989 & -0.010 & 0.012 & 0.007 \\
\hline \multirow[t]{3}{*}{ Education(M) } & Configural & $29.091(21)$ & & 0.990 & & 0.019 & \\
\hline & Weak factorial & 35.77 (33) & $6.679(12)$ & 0.997 & 0.007 & 0.009 & -0.010 \\
\hline & Strict factorial & $78.222(63)$ & $49.131(42)$ & 0.981 & -0.009 & 0.015 & -0.004 \\
\hline
\end{tabular}

activities, which could result in subsequent interpersonal problems [45].

We found a moderate association between the total score on the GAS and substance use. This finding lent support to previous findings on the positive association between IGD and alcohol, tobacco, and illicit drug use

Table 7 Partial measurement invariance across gender, class standing and family income

\begin{tabular}{lllllll}
\hline Model & Model Fit Indices & & & & \\
\hline Gender & \multicolumn{1}{l}{ X2 (df) } & $\Delta \mathbf{X} 2(\Delta \mathrm{df})$ & $\mathrm{CFI}$ & $\Delta \mathrm{CFI}$ & RMSEA & $\Delta$ RMSEA \\
Model 1.1 & $14.876(14)$ & & 0.999 & & 0.008 & \\
Model 1.2 & $29.786(20)$ & $14.910(6)$ & 0.986 & -0.013 & 0.022 & 0.014 \\
Model 1.3 & $20.903(19)$ & $6.027(5)$ & 0.997 & -0.001 & 0.010 & 0.002 \\
Class standing & & & & & \\
Model 2.1 & $19.403(21)$ & & 1.000 & & 0.000 & \\
Model 2.2 & $45.532(33)$ & $26.129(12)$ & 0.984 & -0.016 & 0.019 & 0.019 \\
Model 2.3 & $32.775(31)$ & $13.372(10)$ & 0.998 & -0.002 & 0.007 & 0.007 \\
Family income & & & & & \\
Model 3.1 & $55.048(49)$ & & 0.993 & & 0.011 & \\
Model 3.2 & $76.808(61)$ & $21.76(12)$ & 0.982 & -0.011 & 0.016 & 0.005 \\
Model 3.3 & $67.005(59)$ & & 0.991 & -0.002 & 0.011 & 0 \\
\hline
\end{tabular}

Model 1.1: Unconstrained model

Model 1.2: All item loading equal

Model 1.3: item loadings $1,3,4,5,6,7$ equal

Model 2.1: Unconstrained model

Model 2.2: All item loading equal

Model 2.3: item loadings $1,2,3,4,5,6$ equal

Model 3.1: Unconstrained model

Model 3.2: All item loading equal

Model 3.3: item loadings $1,2,3,4,6,7$ equal
[46-48]. Substance use has been found to be a common comorbidity of Internet addiction, as those with substance use disorder seemed to exhibit similar core symptoms of IGD [50, 51]. Both substance use disorder and IGD have been associated with deficient reward system functions, manifested as having higher responsiveness to substances and video games and lower responsiveness to other natural rewards as a result of altered dopamine levels. Another shared mechanism of these two types of addictive behaviors involves high trait impulsivity. Individuals with high trait impulsivity tend to perform poorly on decision-making tasks, focusing on short-term consequences instead, thus giving priority to addictive behaviors rather than other behaviors [50, 52].

In regards to IGD and sleep quality, some studies found their association to be significant [53]. It is plausible that some gamers may become deprived of sleep due to significant amount of time spent playing games, or report daytime sleepiness as a consequence [54]. Some studies even showed that delayed sleep phase can improve by readjusting individual circadian rhythm with exogenous day-light cycle, thus alleviating gamingrelated sleep problems [55]. However, a systematic review study by Lam found insufficient evidence supporting a strong association between IGD and poor sleep quality [56], but found a stronger association between problematic internet use and sleep problems. In line with Lam's review study, we found the association between gaming addictions and sleep quality to be smaller than the association between problematic internet use and sleep quality, implying that differing mechanisms may be involved in how playing internet games or 
engaging in excessive internet use relays to sleep quality. Although investing these mechanisms is beyond the aim of this study, future studies are needed to examine the underlying mechanisms contributing to these differences.

Previous studies have indicated that gaming addiction was associated with less conscientiousness and low openness, while social networking addiction was associated with high neuroticism and extraversion [14], suggesting that gaming addiction and social networking addiction may be associated with differing personality traits. In the present study, the relatively small correlation between GAS and SMA-SF scores suggested that the GAS can discriminate gamers from people with other types of Internet-related addictive behaviors such as social media addiction.

\section{Strengths and limitations}

To our knowledge, this is the first study to assess the psychometric properties of the 7-item GAS among the college student population in China. Findings of this study provided ample support for the application of the GAS as a screening tool to assess IGD among this population. However, this study also has several limitations that we would like to acknowledge along with prospective directions for future research. First, this study mainly utilized self-report data such as on sleep quality and substance use, reporting or recalling biases might have affected the accuracy of the testing results. Future studies may need to incorporate more objective measures. Second, the cross-sectional nature of our data limited us to draw tentative conclusions about the temporal sequence of IGD development. Longitudinal studies may be needed to clarify this sequence. Third, our study mainly focused on Chinese college students, our findings may not be applicable to same-age populations in other countries. More studies from other countries to corroborate our findings of the GAS.

\section{Conclusions}

This study entails that the 7-item GAS is a reliable and valid instrument for assessing IGD among Chinese college students, ensuring researchers and clinicians that it is an adequate tool to examine problematic gaming.

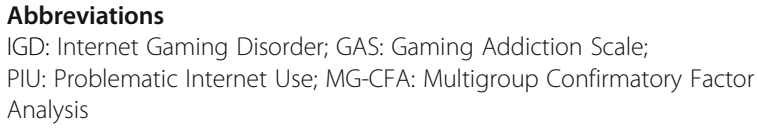

\section{Acknowledgements}

We would like to thank all the participants who completed our surveys used for analysis in this study.

\section{Authors' contributions}

YL: Writing-Original draft preparation, Methodology. QW: Conceptualization, Funding acquisition, Methodology, Project Administration, Supervision,
Writing-reviewing and editing. MJ: Writing-reviewing. BW: Data curation. YA: Data curation. ZL: Methodology. All authors have read and approved the manuscript.

\section{Funding}

This work was supported by Shanghai Jiao Tong University School of Medicine under Grant 19X100040041. The funding body had no role in the design of the study, or the collection, analysis, and interpretation of data, or in the writing of the manuscript.

\section{Availability of data and materials}

The datasets used and/or analyzed during the current study are available from the corresponding author on reasonable request.

\section{Ethics approval and consent to participate}

The study procedures were carried out by the Declaration of Helsinki. The Institutional Review Board of Shanghai Jiao Tong University School of Medicine College of Public Health approved this study (No. SJUPN201907). All participants were informed about the study, and all provided written informed consent

\section{Consent for publication \\ Not applicable.}

\section{Competing interests}

The authors declare that they have no competing interests.

\section{Author details}

${ }^{1}$ School of Public Health, Shanghai Jiao Tong University School of Medicine, No 227 S Chongqing Road, Shanghai 200025, China. ${ }^{2}$ Department of Industrial Education, National Taiwan Normal University, Taipei, Taiwan. ${ }^{3}$ Shanghai Jiao Tong University School of Medicine, College of Clinical Medicine, Shanghai, China. ${ }^{4}$ School of Social Development and Public Policy, Fudan University, Shanghai, China.

Received: 5 March 2020 Accepted: 20 August 2020

Published online: 02 October 2020

\section{References}

1. American Psychiatric Association. Diagnostic and statistical manual of mental disorders, 5th Edn. Arlington, VA: Author; 2013. https://doi.org/10. 1176/appi.books.9780890425596.

2. Müller KW, Janikian $M$, Dreier $M$, et al. Regular gaming behavior and internet gaming disorder in European adolescents: results from a crossnational representative survey of prevalence, predictors, and psychopathological correlates. Eur Child Adolesc Psychiatry. 2015;24:565-74. https://doi.org/10.1007/s00787-014-0611-2.

3. Wang CW, Chan CL, Mak KK, Ho SY, Wong PW, Ho RT. Prevalence and correlates of video and internet gaming addiction among Hong Kong adolescents: a pilot study. Sci World J. 2014;2014:874648. https://doi.org/10. 1155/2014/874648.

4. $\mathrm{Xu} J$, Shen LX, Yan $\mathrm{CH}, \mathrm{Hu} \mathrm{H}$, Yang F, Wang L, et al. Personal characteristics related to the risk of adolescent internet addiction: a survey in Shanghai, China. BMC Public Health. 2012b;12:1106. https://doi.org/10.1186/1471-245812-1106.

5. King DL, Haagsma MC, Delfabbro PH, Gradisar M, Griffiths MD. Toward a consensus definition of pathological video-gaming: a systematic review of psychometric assessment tools. Clin Psychol Rev. 2013;33:331-42.

6. Lemmens JS, Valkenburg PM, Peter J. Development and validation of a game addiction scale for adolescents. Media Psychol. 2009;12(1):77-95. https://doi.org/10.1080/15213260802669458.

7. Walther B, Morgenstern M, Hanewinkel R. Co-occurrence of addictive behaviours: personality factors related to substance use, gambling and computer gaming. Eur Addict Res. 2012;18(4):167-74. https://doi.org/10. $1159 / 000335662$.

8. Costa S, Barberis N, Gugliandolo MC, Liga F, Cuzzocrea F, Verrastro V. Examination of the psychometric characteristics of the Italian version of the game addiction scale for adolescents. Psychol Rep, 33294119838758. Advance online publication. 2019. https://doi.org/10.1177/ 0033294119838758. 
9. Khazaal Y, Chatton A, Rothen S, Achab S, Thorens G, Zullino D, Gmel G. Psychometric properties of the 7-item game addiction scale among french and German speaking adults. BMC psychiatry. 2016;16:132. https://doi.org/ 10.1186/s12888-016-0836-3.

10. Lemos IL, Cardoso A, Sougey EB. Validity and reliability assessment of the Brazilian version of the game addiction scale (GAS). Compr Psychiatry. 2016; 67:19-25. https://doi.org/10.1016/j.comppsych.2016.01.014.

11. Lin CY, Imani V, Brostrom A, Arestedt K, Pakpour AH, Griffiths MD. Evaluating the psychometric properties of the 7-item Persian game addiction scale for Iranian adolescents. Front Psychol. 2019;10:149. https://doi.org/10.3389/ fpsyg.2019.00149.

12. Lloret Irles D, Morell Gomis R, Marzo Campos JC, Tirado González S. Validación española de la Escala de Adicción a Videojuegos para Adolescentes (GASA) [Spanish validation of Game Addiction Scale for Adolescents (GASA)]. Aten Primaria. 2018;50(6):350-8.

13. Shu MY, Ivan Jacob AP, Meng Xuan Z, Anise MSW. Psychometric validation of the internet gaming Disorder-20 test among Chinese middle school and university students. J Behav Addict. 2019;8(2):295-305. https://doi.org/10. 1556/2006.8.2019.18.

14. Wang CW, Ho RT, Chan CL, Tse S. Exploring personality characteristics of Chinese adolescents with internet-related addictive behaviors: trait differences for gaming addiction and social networking addiction. Addict Behav. 2015;42:32-5. https://doi.org/10.1016/j.addbeh.2014.10.039.

15. Bonnaire C, Liddle HA, Har A, Nielsen P, Phan O. Why and how to include parents in the treatment of adolescents presenting internet gaming disorder? J Behav Addict. 2019;8(2):201-12. https://doi.org/10.1556/2006.8. 2019.27.

16. Festl R, Scharkow M, Quandt T. Problematic computer game use among adolescents, younger and older adults. Addiction. 2013;108(3):592-9. https:// doi.org/10.1111/add.12016.

17. Vollmer C, Randler C, Horzum MB, Ayas T. Computer game addiction in adolescents and its relationship to chronotype and personality. SAGE Open. 2014;4(1):2158244013518054. https://doi.org/10.1177/2158244013518054

18. Xu Z, Turel O, Yuan Y. Online game addiction among adolescents: motivation and prevention factors. Eur J Inf Syst. 2012a;21(3). https://doi. org/10.1057/ejis.2011.56

19. Ye YL, Wang PG, Qu GC, Yuan S, Phongsavan P, He QQ. Associations between multiple health risk behaviors and mental health among Chinese college students. Psychol Health Med. 2016;21(3):377-85. https://doi.org/10. 1080/13548506.2015.1070955.

20. Liu W, He MZ, Wang Y, Wang Y, Zhou Y, Wu M, Tang Z, Dai Y, Yuan B, Zhen $\mathrm{S}$, Cheskin LJ. Differences in health-related behaviors between middle school, high school, and college students in Jiangsu province, China. Asia Pac J Clin Nutr. 2017;26(4):731-7. https://doi.org/10.6133/apjcn.072016.06.

21. Meredith W. Measurement invariance, factor analysis and factorial invariance. Psychometrika. 1993;58:525-43. https://doi.org/10.1007/ BF02294825.

22. Lai CM, Mak KK, Watanabe H, Ang RP, Pang JS, Ho RC. Psychometric properties of the internet addiction test in Chinese adolescents. J Pediatr Psychol. 2013;38(7):794-807. https://doi.org/10.1093/jpepsy/jst022.

23. Chin $\mathrm{F}$, Leung $\mathrm{CH}$. The concurrent validity of the internet addiction test (IAT) and the Mobile phone dependence questionnaire (MPDQ). PLoS One. 2018:13(6):e0197562. https://doi.org/10.1371/journal.pone.0197562.

24. Buysse DJ, lii CFR, Monk TH, Berman SR, Kupfer DJ. The Pittsburgh sleep quality index: a new instrument for psychiatric practice and research. Psychiatry Res. 1989;28(2):193-213. https://doi.org/10.1016/01651781(89)90047-4.

25. Guo S, Sun W, Liu C, Wu S. Structural validity of the Pittsburgh sleep quality index in Chinese undergraduate students. Front Psychol. 2016;7:1126. https://doi.org/10.3389/fpsyg.2016.01126.

26. Lau J, Walden DL, Wu A, Cheng KM, Lau M, Mo P. Bidirectional predictions between internet addiction and probable depression among Chinese adolescents. J Behav Addict. 2018;7(3):633-43. https://doi.org/10.1556/2006. 7.2018.87.

27. Derogatis LR. SCL-90-R: administration, scoring \& procedures manual-II, for the $R$ (revised) version and other instruments of the psychopathology rating scale series. 2nd ed. Towson: Clinical Psychometric Research; 1992.

28. Yu Y, Wan C, Huebner ES, Zhao X, Zeng W, Shang L. Psychometric properties of the symptom check list 90 (SCL-90) for Chinese undergraduate students. J Ment Health. 2019:28(2):213-9. https://doi.org/10.1080/09638237. 2018.1521939
29. Zhang J, Zhang X. Chinese college students' SCL-90 scores and their relations to the college performance. Asian J Psychiatr. 2013;6(2):134-40. https://doi.org/10.1016/j.ajp.2012.09.009.

30. Sahin C. Social media addiction scale-student form: the reliability and validity study. Turkish Online J Educ Technol - TOJET. 2018;17:169-82.

31. Wu X, Ni Z. The application of factor analysis in reliability and validity assessment. Chinese J Prev Control Chron Dis. 1998;6(1):28-31 http://doi. org/CNKI:SUN:ZMXB.0.1998-01-008.

32. Kwon M, Kim DJ, Cho H, Yang S. The smartphone addiction scale: development and validation of a short version for adolescents. PLoS One. 2013;8(12):e83558. https://doi.org/10.1371/journal.pone.0083558.

33. Basol G, Kaya AB. Motives and consequences of online game addiction: a scale development study. Noro Psikiyatr Ars. 2018;55(3):225-32. https://doi. org/10.5152/npa.2017.17017.

34. McDonald RP, Ho MH. Principles and practice in reporting structural equation analyses. Psychol Methods. 2002;7(1):64-82. https://doi.org/10. 1037/1082-989x.7.1.64

35. Lee D. The convergent, discriminant, and nomological validity of the depression anxiety stress Scales-21 (DASS-21). J Affect Disord. 2019;259:13642. https://doi.org/10.1016/j.jad.2019.06.036.

36. Cohen J. Statistical power analysis for the behavioral sciences. J Am Stat Assoc ,2nd. 1988;334:499-500. https:/doi.org/10.1016/B978-0-12-179060-8.50012-8.

37. Chen FF. Sensitivity of goodness of fit indexes to lack of measurement invariance. Struct Equ Model Multidiscip J. 2007;14(3):464-504. https://doi. org/10.1080/10705510701301834.

38. Na E, Lee H, Choi I, Kim DJ. Comorbidity of internet gaming disorder and alcohol use disorder: a focus on clinical characteristics and gaming patterns. Am J Addict. 2017;26(4):326-34. https://doi.org/10.1111/ajad.12528.

39. Rho MJ, Lee H, Lee TH, Cho H, Jung DJ, Kim DJ, Choi IY. Risk factors for internet gaming disorder: psychological factors and internet gaming characteristics. Int J Environ Res Public Health. 2017;15(1). https://doi.org/10. 3390/ijerph15010040.

40. Torres-Rodriguez A, Griffiths MD, Carbonell X, Oberst U. Internet gaming disorder in adolescence: psychological characteristics of a clinical sample. J Behav Addict. 2018;7(3):707-18. https://doi.org/10.1556/2006.7.2018.75.

41. Gonzalez-Bueso V, Santamaria JJ, Fernandez D, Merino L, Montero E, Jimenez-Murcia S, et al. Internet gaming disorder in adolescents: personality, psychopathology and evaluation of a psychological intervention combined with parent Psychoeducation. Front Psychol. 2018;9:787. https://doi.org/10. 3389/fpsyg.2018.00787.

42. Gentile DA, Choo H, Liau A, Sim T, Li D, Fung D, Khoo A. Pathological video game use among youths: a two-year longitudinal study. Pediatrics. 2011; 127(2):e319-29. https://doi.org/10.1542/peds.2010-1353.

43. Kim YJ, Lim JA, Lee JY, Oh S, Kim SN, Kim DJ, et al. Impulsivity and compulsivity in internet gaming disorder: a comparison with obsessivecompulsive disorder and alcohol use disorder. J Behav Addict. 2017;6(4): 545-53. https://doi.org/10.1556/2006.6.2017.069.

44. Schafer JL \& Graham JW. Missing Data Our View of the State of the Art. Psychological Methods 2002;7: 147-177.

45. Skarupova K, Blinka L. Interpersonal dependency and online gaming addiction. J Behav Addict. 2016;5(1):108-14. https://doi.org/10.1556/2006.5.2016.002.

46. Konkoly Thege B, Hodgins DC, Wild TC. Co-occurring substance-related and behavioral addiction problems: a person-centered, lay epidemiology approach. J Behav Addict. 2016;5(4):614-22. https://doi.org/10.1556/2006.5.2016.079.

47. Lam LT. Risk factors of internet addiction and the health effect of internet addiction on adolescents: a systematic review of longitudinal and prospective studies. Curr Psychiatry Rep. 2014b;16(11):508. https://doi.org/10 1007/s11920-014-0508-2.

48. Van Rooij AJ, Kuss DJ, Griffiths MD, Shorter GW, Schoenmakers TM, Dike VDM. The (co-)occurrence of problematic video gaming, substance use, and psychosocial problems in adolescents. J Behav Addict. 2014;3(3):157-65. https://doi.org/10.1556/JBA.3.2014.013.

49. Fornell C \& Larcker DF (1981). Evaluating Structural Equation Models with Unobservable Variables and Measurement Error. Journal of Marketing Research, 18, 39-50.

50. Jorgenson $A G$, Hsiao RC, Yen CF. Internet addiction and other behavioral addictions. Child Adolesc Psychiatr Clin N Am. 2016;25(3):509-20. https://doi. org/10.1016/j.chc.2016.03.004.

51. Kuss DJ, Griffiths MD, Karila L, Billieux J. Internet addiction: a systematic review of epidemiological research for the last decade. Curr Pharm Des. 2014;20(25):4026-52. https://doi.org/10.2174/13816128113199990617. 
52. Hammond CJ, Mayes LC, Potenza MN. Neurobiology of adolescent substance use and addictive behaviors: treatment implications. Adolescent Med. 2014;25(1):15-32. https://doi.org/10.1189/jb.0112042.

53. Hawi NS, Samaha M, Griffiths MD. Internet gaming disorder in Lebanon: relationships with age, sleep habits, and academic achievement. J Behav Addict. 2018;7(1):70-8. https://doi.org/10.1556/2006.7.2018.16.

54. Achab S, Nicolier M, Mauny F, Monnin J, Trojak B, Vandel P, Sechter D, Gorwood P, Haffen E. Massively multiplayer online role-playing games: comparing characteristics of addict vs non-addict online recruited gamers in a French adult population. BMC Psychiatry. 2011;11:144. https://doi.org/ 10.1186/1471-244X-11-144

55. Lemola S, Brand S, Vogler N, Perkinson-Gloor N, Allemand M, Grob A. Habitual computer game playing at night is related to depressive symptoms. Pers Individ Differ. 2011;51(2):117-22. https://doi.org/10.1016/j. paid.2011.03.024

56. Lam LT. Internet gaming addiction, problematic use of the internet, and sleep problems: a systematic review. Curr Psychiatry Rep. 2014a;16(4):444. https://doi.org/10.1007/s1 1920-014-0444-1.

57. Wimmer RD \& Dominick JR (2014). Mass Media Research: An Introduction. 10th Edition, Wadsworth, Cengage Learning, Boston.

58. Young KS. Internet addiction: the emergence of a new clinical disorder. CyberPsychol Behav. 1996;1 (3):237-44. https://doi.org/10.1089/cpb.1998.1.237.

\section{Publisher's Note}

Springer Nature remains neutral with regard to jurisdictional claims in published maps and institutional affiliations.

Ready to submit your research? Choose BMC and benefit from:

- fast, convenient online submission

- thorough peer review by experienced researchers in your field

- rapid publication on acceptance

- support for research data, including large and complex data types

- gold Open Access which fosters wider collaboration and increased citations

- maximum visibility for your research: over $100 \mathrm{M}$ website views per year

At BMC, research is always in progress.

Learn more biomedcentral.com/submissions 